\title{
Burocracia Representativa: uma (re)produção de Desigualdades de Gênero e Raça no Setor Público Federal?
}

Representative Bureaucracy: A (re) production of Gender and Race Inequalities in the Federal Public Sector?

\author{
Rafael Rocha Viana ${ }^{1}$ \\ Carolina Pereira Tokarski ${ }^{2}$
}

\begin{abstract}
RESUMO
O artigo tem como objetivo discutir as desigualdades de gênero e raça no setor público federal à luz da teoria da burocracia representativa. $O$ termo burocracia representativa possui diferentes concepções na literatura, o qual será tomado, neste artigo, em sua dimensão passiva, que busca refletir se a representação dos servidores na administração pública reflete a participação dos grupos sociais tais como eles se apresentam na sociedade. Os dados a serem discutidos são oriundos de survey realizado pela Enap (2018), com amostra estratificada simples de 2000 respondentes do Serviço Civil Federal por órgãos superiores do Poder Executivo, a partir dos quais mostramos que a representação por gênero e raça nessa esfera. Foram utilizados também duas outras pesquisas realizadas pela Enap. Os resultados dos estudos sugerem que, quanto maior os cargos comissionados, menor a representação de mulheres e negros. Além disso, a pesquisa revela que os maiores salários estão concentrados nos grupos homens e brancos, sobretudo, em razão destes serem preponderantes nos cargos comissionados e nas carreiras federais com maior status social, o que nos permite afirmar que o Setor Público Federal também reproduz padrão de desigualdade no que diz respeito à composição da força de trabalho.
\end{abstract}

Palavras-chave: Burocracia representativa; raça; gênero; serviço civil.

\section{ABSTRACT}

The article aims to discuss gender and race inequalities in the federal public sector considering the theory of representative bureaucracy. The term representative bureaucracy has different conceptions in the literature, which will be taken, in this article, in its passive dimension, which seeks to reflect if the representation of civil servants in public administration reflects the participation of social groups as they present themselves in society. The data to be discussed are derived from a survey conducted by Enap (2018), with a simple stratified sample of 2000 Federal Civil Service respondents by senior executive bodies, from which we show that representation by gender and race in this sphere. Two other surveys conducted by Enap were also used. The results of the studies suggest that the higher the commissioned positions, the lower the representation of women and blacks. In addition, the survey reveals that the highest salaries are concentrated in the white and male groups, especially because they are preponderant in commissioned positions and federal careers with higher social status, which allows us to state that the Federal Public Sector also reproduces standards. inequality regarding the composition of the workforce.

Keywords: Representative bureaucracy; race; genre; civil service.

\footnotetext{
${ }^{1}$ Universidade de Brasília (UNB), Instituto de Ciência Política (IPOL), Programa de Pós-Graduação em Ciência Política. E-mail: rafael.viana@enap.gov.br

2 Instituto de Pesquisa Econômica Aplicada (IPEA), Diretoria de Estudos e Políticas Sociais (Disoc). E-mail: carolina.tokarski@ipea.gov.br
} 


\section{Introdução}

A discussão sobre Burocracia Representativa tem sido realizada há algumas décadas em pesquisas na Europa e nos Estados Unidos (Kingsley, 1944; Keiser et all, 2002) a fim de investigar se a proporcionalidade das minorias sociais na composição da burocracia reflete a da sociedade. A preocupação inicial, ainda na década de 40 , em uma perspectiva crítica, era de problematizar se as desigualdades sociais britânicas também estavam presentes na composição do corpo burocrático, visando a adoção de iniciativas que pudessem minimizá-las (Kingsley, 1944). Já na década de 80, alguns estudos discutiram se a representação de alguns grupos sociais na composição da força de trabalho poderia aumentar o desempenho das políticas públicas (Meier; Wrinkle; Polinard, 1999). Mais recentemente, algumas pesquisas têm explorado a relação entre a diversidade das organizações e o melhor desempenho institucional (Andrews; Boyne; Meier; O'toole; Walker, 2015; Groeneveld, 2015).

O presente artigo, portanto, insere-se nesse debate, buscando demonstrar como as desigualdades sociais brasileiras estão presentes no Serviço Civil do Poder Executivo Federal, a partir de um recorte de gênero e raça. Tendo como base de dados survey realizado pela Escola Nacional de Administração Pública (ENAP, 20183), dados do Informe de Pessoal da Enap e de levantamento feito na base do Siape de março de 2018, a pesquisa tem as seguintes perguntas norteadoras: Os servidores do Serviço Civil Federal podem ser considerados representativos da população a partir do recorte de gênero e raça? A administração pública federal enquanto empregadora reproduz ou enfrenta as desigualdades de gênero e raça encontradas no mercado de trabalho? Os servidores públicos podem ser considerados representativos da população? Em que medida burocracias que espelham a desigualdade reforçam a (re) produção das desigualdades?

Além desta introdução, o artigo está organizado da seguinte maneira. A segunda seção explora as literaturas sobre burocracia representativa e desigualdades de gênero e raça no mercado de trabalho a fim de apresentar diferentes definições e as possíveis implicações no setor público. A terceira seção apresenta a metodologia e os dados utilizados pelo estudo. A quarta seção discute os principais resultados, à luz das reflexões trazidas pela literatura. A última seção apresenta as considerações finais, as limitações do estudo e as potenciais agendas de pesquisa futuras.

\section{Burocracia Representativa e a reprodução de desigualdades no mercado de trabalho do setor público federal}

A representação nas instituições políticas - especialmente nas arenas legislativas e nas burocracias estatais - tem sido motivo de preocupação há muitos anos. Antes trabalhado de maneira difusa, o conceito de "Burocracia Representativa" foi utilizado pela primeira vez no estudo de Kingsley (1944), intitulado "Representative Bureaucracy: An Interpretation of the British Civil Service", a fim de demonstrar as desigualdades sociais presentes na composição do British Civil Service na década de 40. Para Kringsley (1944), ao olhar para composição desta força de trabalho, era possível verificar que, quanto maior o cargo, menor a representação de membros da classe trabalhadora e maior a presença de membros advindos de classes sociais mais altas. Dessa forma, o autor reivindicava a necessidade da criação de um sistema que permitisse a representação dos indivíduos de origem trabalhadora nos altos cargos.

A partir da década 70 , vários estudos abordaram a temática da representação burocrática, mas a partir de uma perspectiva demográfica, na qual incorporaram a questão de gênero e de raça (Smith, 1980; Meier, 1975; Krislov, 1974). Dentro dessa perspectiva, um dos estudos mais influentes foi o de Mosher (1968), no qual ele distingue dois tipos de representação burocrática, quais sejam: passiva ou representação demográfica e ativa ou representação administrativa. De acordo com Mosher (1968), a representação

\footnotetext{
${ }^{3}$ Amostra composta por 6474 respondentes, escolhidos por estratificação simples por órgãos da administração direta do Poder Executivo Federal, com taxa de resposta de $34 \%$.
} 
passiva, entendida como representação descritiva, diz respeito às burocracias espelhando demograficamente o público ao qual servem. Segundo Mosher (1968, p.12), "O significado passivo (ou sociológico) da representatividade diz respeito à fonte de origem dos indivíduos e ao grau de que, coletivamente, espelham a sociedade total".

Já a representação ativa dá-se quando os burocratas traduzem os interesses dos grupos sociais aos quais pertencem em decisões políticas a favor destes que eles representam passivamente. Segundo Mosher (1968, p.12), "na representatividade ativa (ou responsiva) espera-se que um indivíduo (ou administrador) pressione pelos interesses daqueles que supostamente representam, sejam a população geral ou algum segmento do povo "(p.12).

Desse modo, há potenciais benefícios simbólicos inerentes à representação passiva bem como potenciais benefícios tangíveis da representação ativa, especialmente dos burocratas de linha de frente. Simbolicamente, a representação passiva pode refletir acesso equânime ao poder, conferindo legitimidade às instituições burocráticas (Selden, 1977). Além dos benefícios simbólicos, algumas pesquisas indicam que pode existir ligação entre representação passiva e ativa em que grupos sub-representados possam receber provisão de serviços mais equitativos, aumentando a representação (Meier; Nicholson-Crotty, 2006).

Assim, neste artigo discutiremos a representação do serviço civil federal brasileiro na sua dimensão passiva. Portanto, na seção de resultados, apresentaremos como se encontra a representação de mulheres e negros no poder executivo federal, dando continuidade a uma trajetória de pesquisas que tem se debruçado sobre estas questões.

O trabalho buscará evidenciar como as desigualdades de gênero e raça materializam-se na administração pública brasileira a fim de que pesquisas futuras possam discutir o efeito destas desigualdades nas políticas públicas.

\subsection{Panorama das mulheres no mundo do trabalho}

As mulheres no Brasil sempre trabalharam. No entanto, a forte divisão sexual do trabalho e a invisibilidade do trabalho desempenhado por mulheres negras e pobres, alijadas do processo de assalariamento puro, retiraram as mulheres das narrativas clássicas sobre o mercado de trabalho (Ipea, 2014). Estatísticas oficiais dão conta, no entanto, que as mulheres representavam 45,5\% da força de trabalho no ano de 1872 (Ipea, 2014). A segunda onda de ingresso das mulheres no trabalho produtivo é observada a partir de meados da década de 70 no Brasil, desde então, diversas pesquisadoras têm se debruçado na análise de como aconteceu esta inserção.

No quesito educação, observam que o aumento da escolaridade impacta no ingresso no mercado de trabalho, desta forma, têm-se uma maior taxa de atividade das mulheres mais escolarizadas. Apontam que apesar de ter acontecido um movimento de ascensão das mulheres mais escolarizadas em carreiras de prestígio, como nas áreas da medicina, advocacia e engenharia, o trabalho das mulheres continua a concentrar-se nos "guetos femininos", ocupações muitas vezes ligadas ao cuidado como a nutrição, assistência social, psicologia, magistérios (educação infantil, fundamental e médio), costura, serviços de cuidado pessoal, alimentação, dentre outras atividades (Bruschini et al, 2008). Pesquisa do Dieese (Leite, 2017) a partir das PNADs de 2004, 2012, 2013, 2014 e 2015 corrobora a permanência da segmentação das mulheres em atividades relacionadas à educação, saúde e serviços sociais.

Quanto às tendências de inserção laboral das mulheres em relação às ocupações desempenhadas, além da guetização, uma outra característica da estrutura ocupacional do mercado de trabalho é a concentração de mulheres em postos de trabalhos precarizados. Ou seja, as mulheres concentram-se menos que os homens entre os ocupados com carteira de trabalho, possuem maior participação no trabalho doméstico 
remunerado (com ou sem carteira de trabalho), nas ocupações não remuneradas e nas que se destinam a produções para o próprio consumo. Desta forma, além de receberem menores remunerações, o trabalho das mulheres concentra-se em atividades mais precárias (Leite, 2017; Bruschini et al, 2008).

Assim, quanto a entrada e permanência no mercado de trabalho observa-se um triplo movimento que delineia a estrutura ocupacional do mercado de trabalho: as mulheres historicamente apresentam menores taxas de ingresso no mercado em de trabalho, fator explicado em grande medida pela sobrecarga de trabalhos reprodutivos, desempenhados para que outros integrantes da família tenham condições de integrar o mercado de trabalho. Quando conseguem colocar-se a disposição do mercado de trabalho, tem mais dificuldade de inserção profissional, o índice de desemprego entre as mulheres é historicamente maior do que entre os homens. E, por fim, têm sua trajetória laboral constantemente interrompida com saídas e entradas mais frequentes no mercado de trabalho, uma vez que, seja em decorrência de oscilações econômicas nas famílias, seja por conta de casos de enfermidades familiares, são as mulheres as primeiras a ocupar o papel de cuidadora nas atividades de cuidados das famílias brasileiras (Ipea, 2014). Tal fato traz impactos diretos na aposentadoria das mulheres, uma vez que a maior frequência de entradas e saídas do mercado de trabalho quase sempre impacta na redução do tempo de contribuição destas.

Uma outra característica importante da inserção das mulheres no mercado de trabalho brasileiro é a categoria do trabalho doméstico. Constitui-se como a categoria profissional que mais emprega mulheres, em 2018, mais de 5,7 milhões de mulheres, ou 14,6\% das brasileiras ocupadas exerciam alguma atividade remunerada no trabalho doméstico (Ipea, 2019). Dentre o contingente total de trabalhadoras e trabalhadores domésticos, 63\% são mulheres negras (Ipea, 2019).

Segundo Helena Hirata e Danièle Kergoat (2008), ainda que a manifestação da divisão sexual do trabalho aconteça de modos diferentes através do tempo e em manifestações específicas em cada país, ela opera segundo dois princípios: o princípio da separação e o princípio hierárquico. Segundo o princípio da separação haveria os trabalhos desempenhados por homens e os trabalhos desempenhados por mulheres. Já, segundo o princípio hierárquico, os trabalhos desempenhados pelos homens possuem maior valor social do que os desempenhados pelas mulheres. (Hirata, Kergoat, 2008).

(...) falar em termos de divisão sexual do trabalho é: primeiro, mostrar que essas desigualdades são sistemáticas e, segundo, articular essa descrição do real como uma reflexão sobre os processos mediante os quais a sociedade utiliza essa diferenciação para hierarquizar as atividades, e portanto os sexos; em suma, para criar um sistema de gênero (Hirata, Kergoat, p. 263, 2008)

Essa manifestação da divisão sexual do trabalho acontece em grande medida devido a naturalização do trabalho reprodutivo como responsabilidade principal das mulheres, consequentemente, como resultado das interações entre trabalho produtivo e trabalho reprodutivo na sociedade brasileira, tem-se que o trabalho das mulheres é visto pela sociedade como secundário. Em síntese a estrutura ocupacional das mulheres apresenta as seguintes características: as mulheres possuem menores chances de apresentarem-se ao mercado de trabalho, fator espelhado na menor taxa de participação das mulheres na população economicamente ativa (PEA); quando entram no mercado de trabalho ocupam os vínculos mais precários; recebem salários menores; exercem, em grande medida, atividades ligadas a serviços de cuidados pessoais; possuem maiores dificuldades de ascensão profissional; suas trajetória profissionais são marcadas por maior frequência de descontinuidades; acúmulo entre jornada no trabalho produtivo com jornada no trabalho reprodutivo, resultando em mais horas trabalhadas ao total; maior frequência de jornadas reduzidas no mercado de trabalho; maior dificuldade de inserção no mercado de trabalho, 
resultando em maiores taxas de desemprego (Ipea, 2014).

A partir das marcantes desigualdades que configuram a estrutura ocupacional do mercado de trabalho para as mulheres, o emprego público é visto como um espaço em que poderiam alcançar maior condições de igualdade (Ipea, 2014). No entanto, como veremos, quando analisamos a participação das mulheres na força de trabalho do serviço civil da administração pública federal, encontramos a reprodução de um cenário de desigualdades de gênero no acesso, na permanência e na ascensão das mulheres no serviço público federal.

\section{Metodologia}

Nessa seção do artigo, apresentamos as fontes de dados e a metodologia utilizada pela pesquisa a fim de compreender a representação burocrática do Serviço Civil do Poder Executivo Federal. Nesse sentido, as fontes de dados utilizadas foram três, ambas pesquisas realizadas pela Enap, quais sejam: Informe de Pessoal Enap ${ }^{4}$ (2018), estudo que estudo que traz a análise dos dados sobre pessoal civil ativo do Poder Executivo Federal, agrupados em órgãos superiores ${ }^{1}$, em cinco recortes: escolaridade; remuneração; cargos e funções; gênero; e raça/cor e; 2) pesquisa "Capacidades Estatais para a produção de políticas públicas: resultados do survey sobre o serviço civil no Brasil ${ }^{5 "}$, que a partir de um survey aplicado a uma amostra representativa do Brazilian Federal Civil Service ${ }^{6}$, demonstrou as principais atividades realizadas por este grupo de servidores públicos federais; 3) levantamento de dados do SIAPE de março de 2018 a partir do mesmo recorte do serviço civil no Brasil.

Como técnicas de análise de dados, utilizamos análise exploratórias multivariadas - análise fatorial - com vistas à identificação de possíveis associações entre variáveis do questionário. Nesse sentido, utilizamos análise fatorial para reduzir o número de variáveis iniciais, com a menor perda possível de informações, em fatores. A aplicação dessa técnica possibilitou avaliar as interrelações entre as variáveis, de modo que estas pudessem ser adequadamente descritos por novos grupos de categorias básicas, a saber, 'fatores' (Pestana; Gageiro, 2005). Além disso, foram utilizadas estatísticas descritivas gerais a fim de compararmos grandes grupos, como, por exemplo, a representação de brancos e não-brancos e mulheres e homens. A seção abaixo mostrará a análise desses dados.

\section{Resultado da representação passiva de gênero e raça no serviço civil da administração pública federal}

A análise das desigualdades de gênero e raça na administração pública enquanto empregadora a partir da lente da representação burocrática nos possibilita enxergar outros efeitos além dos observados nas desigualdades presentes no mercado de trabalho. A partir desta lente, as desigualdades ocupacionais também adquirem efeitos simbólicos e na tomada de decisão ainda não dimensionados, uma vez que os servidores públicos além de trabalhadores, carregam a dimensão de representar e implementar o interesse público.

A participação das mulheres no serviço civil da administração pública federal segue a mesma dinâmica de menor participação observada no mercado de trabalho e no serviço público federal. Desse modo, enquanto as mulheres representam $51,5 \%$ da população brasileira, segundo dados da PNAD/ IBGE de 2017, quando analisada a participação destas no mercado de trabalho este número é reduzido para $44 \%$, segundo a PNAD

\footnotetext{
${ }^{4}$ Para saber mais sobre o estudo, ver https://www.enap.gov.br/documentos/noticias/1 111 Informe de Pessoal - INFOGOV menor arquivo.pdf

${ }^{5}$ Para saber sobre a pesquisa e sobre a construção do survey, ver (Enap, 2018).

${ }^{6}$ Para a Enap (2018), o Brazilian Civil Service é o core de servidores do Poder Executivo Federal, que inclui profissionais que atuam em agências e entidades que subsidiam a formulação e a implementação de políticas públicas e gestão pública.
} 
de 2016. No serviço público federal, e no serviço civil, em específico, essa dinâmica é reproduzida, uma vez que as mulheres representam nestes, respectivamente, $44,8 \%$ e $45,9 \%$. A falsa ideia de que o concurso público seria uma forma de mitigar as barreiras para a entrada da mulher enquanto trabalhadora no serviço público não se confirma, todavia.

Tabela 1: Composição do serviço civil da administração pública federal brasileira a partir da comparação entre população total, população economicamente ativa e serviço público federal, por sexo.

\begin{tabular}{|c|c|c|c|c|c|c|}
\hline \multirow[t]{2}{*}{ Informação/Sexo } & \multicolumn{2}{|l|}{ Mulheres } & \multicolumn{4}{|l|}{ Homens } \\
\hline & $N$ & $\%$ & $N$ & $\%$ & $\mathrm{~N}$ & $\%$ \\
\hline $\begin{array}{ll}\text { População } & \text { Brasileira } \\
\text { (IBGE, 2017) } & \end{array}$ & 106.945 .378 & 51,5 & 100.715 .551 & 48,5 & 207.660 .929 & 100 \\
\hline $\begin{array}{l}\text { População } \\
\text { economicamente ativa } \\
\text { (2016) }\end{array}$ & 45.684 .321 & 44 & 58.897 .483 & 56 & 104.581 .804 & 100 \\
\hline $\begin{array}{lr}\text { Servidores } & \text { públicos } \\
\text { federais (Siape/Mar/2018) }\end{array}$ & 290.660 & 44,8 & 358.220 & 55,2 & 648.880 & 100 \\
\hline $\begin{array}{l}\text { Serviço civil federal } \\
\text { (Siape/Mar/2018) }\end{array}$ & 44.242 & 45,9 & 52.045 & 54,1 & 96.287 & 100 \\
\hline
\end{tabular}

Fonte: SIAPE referente a março de 2018.

Observamos que esta tendência de menor participação das mulheres no serviço civil da administração pública é mantida ao longo do tempo, e, da mesma forma que se observa um teto de participação no mercado de trabalho (Ipea, 2014), o fenômeno parece reproduzir-se quando observamos a administração pública.

Gráfico 1: Percentual de participação por sexo no serviço civil da administração pública federal.

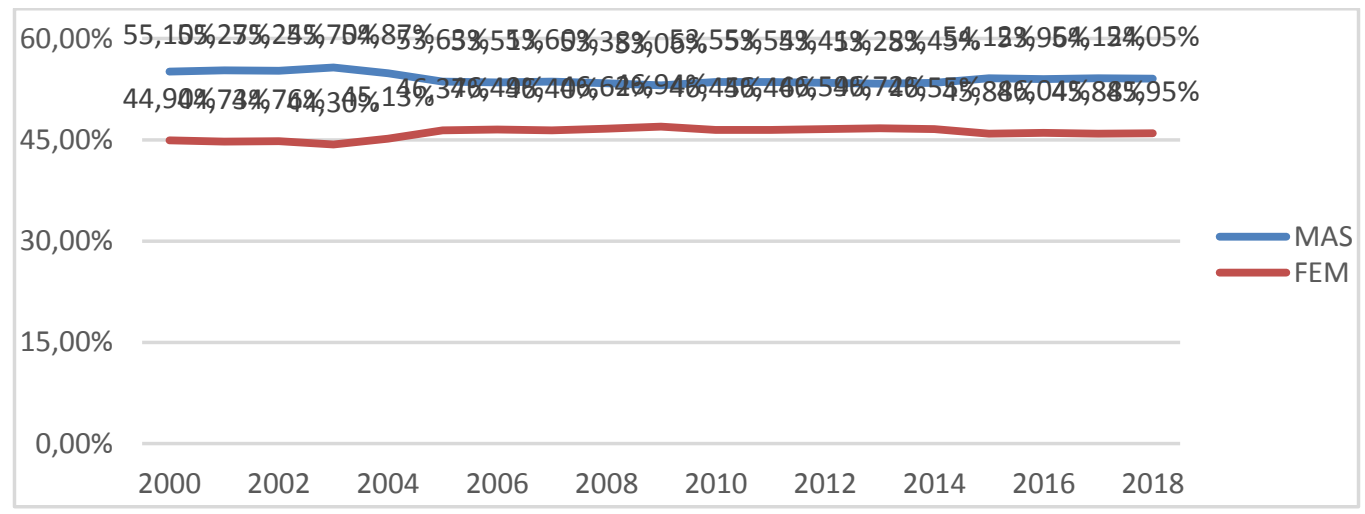

Fonte: SIAPE referente a março de 2018. 
O princípio da separação (Hirata, Kergoat, 20120) segundo o qual homens e mulheres desempenham tipos de atividades diferentes e específícos parece alcançar efeito no serviço civil da administração pública a partir da área temática específica de cada ministério. No mercado de trabalho observa-se uma concentração de mulheres em ocupações ligadas aos cuidados pessoais e as atividades que substituem o trabalho reprodutivo. Quando observamos a composição do serviço civil federal nos Ministérios, têm-se que dentre vinte e dois ministérios pesquisados, apenas Em seis ministérios a composição de mulheres é maior do que de homens, e destes seis, cinco são da área de políticas sociais, são eles: Ministério da Saúde, com $62 \%$ de participação de mulheres, Ministério dos Direitos Humanos, 61\%, Ministério do Desenvolvimento Social, $56 \%$, Ministério da Cultura, 55\% e Ministério da Educação, com 55\% da participação de mulheres no serviço civil.

Gráfico 2: Composição da força de trabalho, por órgão superior do serviço civil da administração pública federal

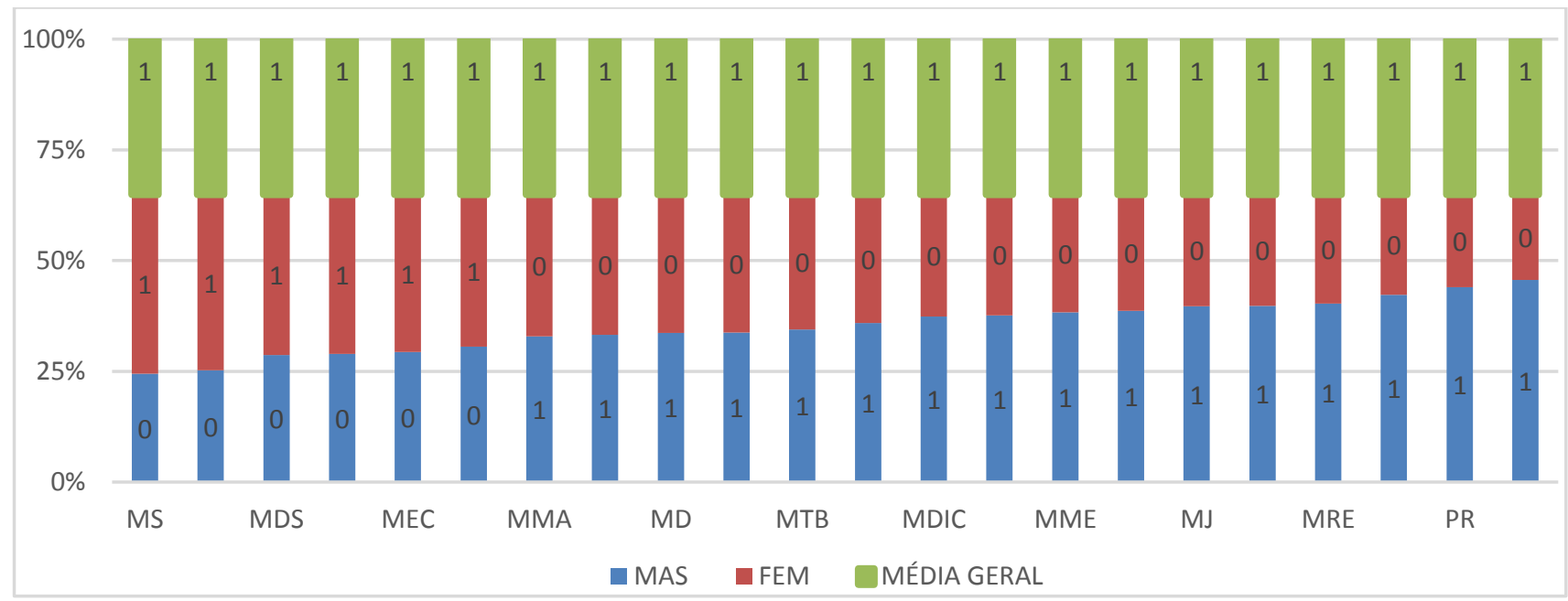

Fonte: elaboração dos autores, a partir dos dados do SIAPE referente a março de 2018.

O princípio da hierarquização, segundo o qual os trabalhos desempenhados pelas mulheres seriam inferiores aos desempenhados pelos homens, também parece estar presente quando observamos a composição salarial dos ministérios. Na tabela abaixo os ministérios foram ordenados a partir das remunerações recebidas pelos servidores e servidoras públicas federais. As remunerações foram agruparas em três categorias, até $R \$ 6$ mil reais, de $R \$ 6$ mil reais a $R \$ 12$ mil reais e acima $R \$ 12$ mil reais. Os primeiros ministérios listados são os que possuem o maior percentual de pessoas recebendo acima de $R \$$ 12 mil reais, seguindo em ordem decrescente até o ministério em que o menor percentual de pessoas recebe acima deste valor.

Os ministérios cuja a participação das mulheres na composição da força de trabalho excede a participação dos homens figuram todos nas categorias inferiores. Ou seja, enquanto os ministérios com maior participação de homens os salários acima de $\mathrm{R} \$ 12$ mil são recebidos entre $29 \%$ a $79,77 \%$ dos servidores do órgão, nos ministérios em que encontramos maior participação de mulheres, este percentual varia entre $8,86 \%$ e $27 \%$ de servidoras e servidores públicos. 
Gráfico 3: Distribuição das faixas salariais por Ministério

\begin{tabular}{|c|c|c|c|}
\hline & Ấé R\$ 6 mil & 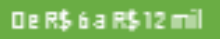 & A cima de R \$12 mil \\
\hline \multirow[t]{2}{*}{ Ministério da Transparência e Conirolad oria Geral da Uniă } & $1,70 x$ & $18,635 \%$ & $74, \pi 5 \%$ \\
\hline & $2051 \%$ & $16,87 \%$ & $63,62 \%$ \\
\hline Ministéria da Jusliça e Se gurança Pública & $12, \mathrm{DS} \times$ & 31,126 & $66,86 \%$ \\
\hline Hiristérin das Relaçŏes Ex1eriores & $13,15 \times$ & $36,37 \%$ & $60,08 \times$ \\
\hline Ministério do Mein Ambien1e & $14,38 \times$ & $36,94 \%$ & 49688 \\
\hline Ministério da Ciên cia, Tecmolegia,Innva çŏes e Camunic aç ŭes & P且6右 & 43,968 & $46.20 \%$ \\
\hline Presidência da República & $27,66 \times$ & $29 \mathrm{k1 \%}$ & $4272 \%$ \\
\hline Minis1ério de kinas e Energia & $34,69 \%$ & 24,746 & $40,67 \%$ \\
\hline Ministério da Indústria, Comércio Exı́erior e Serviços & $14,99 \%$ & $46,06 \times$ & $39,97 \times$ \\
\hline Minisério do Trabalho & $63 \square 2 \%$ & $\pi, 648$ & $36,44 \%$ \\
\hline Minis1ério dos Espories & $32,67 \%$ & $33,00 \%$ & $34,35 \%$ \\
\hline Min isté ria da Ag ricultara, Pecuária e A bas1ec imen10 & $29,40 \%$ & $4,04 \%$ & 29,6606 \\
\hline Min istéria do Transporle, Porios e Aviaçăa Civil & 26,898 & $45,12 \%$ & $29,00 \%$ \\
\hline Minis1ério da Educa çă & $37,66 x$ & $36,95 \%$ & $26,39 \%$ \\
\hline Miristéria do Desenvoluimen10 5acial & $4,96 \%$ & $76,27 \%$ & $18,76 \times$ \\
\hline 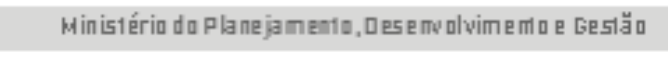 & $65,06 \times$ & $29,69 \%$ & $16,36 \times$ \\
\hline Hinis1ério dos Direin o.5 Humanos & $40,87 \%$ & $43,7 \times$ & $16,22 \%$ \\
\hline Ministério da Cultura & $37,36 \%$ & $40,59 x_{0}$ & $14,46 \times$ \\
\hline Ministério da In1egraçăo Nac ional & 16,818 & $69,26 \%$ & $13,9.5 \times$ \\
\hline M in istério da Turisma & $47,69 \%$ & 40,000 & $12,51 \%$ \\
\hline Mlinistério das Cidades & $44,13 \%$ & $44,15 \times$ & $11,75 \times$ \\
\hline M in istério da Defera & 6. $3,24 \%$ & 37,226 & $9,63 \times$ \\
\hline Minişério da Saúde & $56,11 \%$ & $36,03 \times 6$ & $\mathrm{~B}, \mathrm{~B} 6 \mathrm{x}_{\mathrm{x}}$ \\
\hline Tatal & $36,84 \%$ & $36,60 \times 6$ & $27,67 \%$ \\
\hline
\end{tabular}

Fonte: Informe de Pessoal/Enap 2018.

Para efeito da análise da remuneração do serviço civil da administração pública federal considerou-se a reflexão proposta por Osório (2005), segundo a qual a fórmula de composição da remuneração na administração pública sugerida pela literatura: carreira + cargo + tempo de serviço + jornada quando aplicada para o cálculo da remuneração na administração pública federal pode ser replicada desprezando o efeito do tempo de serviço em função das carreiras no Brasil serem estruturadas de forma pouco verticalizadas.

Por sua vez, ao se observar a tabela abaixo que descreve a jornada de trabalho, constata-se que $91,3 \%$ dos servidores públicos federais ocupam as jornadas de 40 horas ou de dedicação exclusiva. Nestas jornadas, por sua vez, a composição por sexo segue a tendência observada de composição no serviço público federal, $44,8 \%$ de mulheres e $55,2 \%$ de homens. Na jornada de 40 horas, jornada que exercem $74,2 \%$ dos servidores públicos federais, $42,2 \%$ são mulheres e $57,4 \%$ são homens. Já na jornada de dedicação exclusiva, a qual fazem parte $17,1 \%$ dos servidores públicos federais, $44,6 \%$ são mulheres e $55,4 \%$ são homens. Assim, para efeito deste trabalho também descartaremos a jornada de trabalho em nossas análises quanto à remuneração, sendo ela calculada a partir da função: cargo + função + gratificações. 
Tabela 2: Jornada de Trabalho por sexo

\begin{tabular}{|c|c|c|c|c|c|c|}
\hline \multirow{2}{*}{$\begin{array}{l}\text { Jornada de } \\
\text { Trabalho }\end{array}$} & \multicolumn{2}{|l|}{ Homem } & \multicolumn{2}{|l|}{ Mulher } & \multicolumn{2}{|c|}{ Total Geral } \\
\hline & $\mathbf{N}$ & \% Row & $\mathbf{N}$ & \% Row & $\mathbf{N}$ & $\%$ Col. \\
\hline$<20 \mathrm{~h} \mathrm{sem}$ & 23 & $65,6 \%$ & 12 & $34,4 \%$ & 35 & $0,0 \%$ \\
\hline $20 \mathrm{~h}$ sem & 9.449 & $58,0 \%$ & 6.853 & $42,0 \%$ & 16.302 & $2,4 \%$ \\
\hline $24 \mathrm{~h}$ sem & 4.152 & $52,1 \%$ & 3.815 & $47,9 \%$ & 7.967 & $1,2 \%$ \\
\hline $25 \mathrm{~h} \mathrm{sem}$ & 495 & $45,1 \%$ & 603 & $54,9 \%$ & 1.098 & $0,2 \%$ \\
\hline $30 \mathrm{~h} \mathrm{sem}$ & 2.330 & $32,0 \%$ & 4.941 & $68,0 \%$ & 7.271 & $1,1 \%$ \\
\hline $36 \mathrm{~h}$ sem & 3.323 & $21,6 \%$ & 12.037 & $78,4 \%$ & 15.360 & $2,3 \%$ \\
\hline $40 \mathrm{~h}$ sem & 286.358 & $57,4 \%$ & 212.312 & $42,6 \%$ & 498.670 & $74,2 \%$ \\
\hline $44 \mathrm{~h} \mathrm{sem}$ & 8.326 & $81,7 \%$ & 1.859 & $18,3 \%$ & 10.185 & $1,5 \%$ \\
\hline $\begin{array}{l}\text { Ded. } \\
\text { Exclusiva }\end{array}$ & 63.713 & $55,4 \%$ & 51.389 & $44,6 \%$ & 115.102 & $17,1 \%$ \\
\hline
\end{tabular}

Fonte: elaboração dos autores, a partir dos dados do SIAPE referente a março de 2018.

A série temporal da remuneração média no serviço civil mostra um aumento substancial dos salários dos servidores públicos federais. No entanto, observa-se que a diferença salarial entre homens e mulheres não seguiu uma redução linear, apresentando momentos de queda e momentos de crescimento da diferença salarial. No início da série histórica a diferença entre as remunerações medidas, por sexo, era de $22 \%$, no ano 2000. No ano de 2006 essa diferença alcançou o pico superior de $27 \%$. Nos anos de 2015 e 2016 a diferença alcançou o menor patamar, $21 \%$, mas 2018 ela volta a crescer e situa-se no patamar de $22 \%$. 
Gráfico 4: Série temporal da remuneração média por sexo do serviço civil da administração pública federal

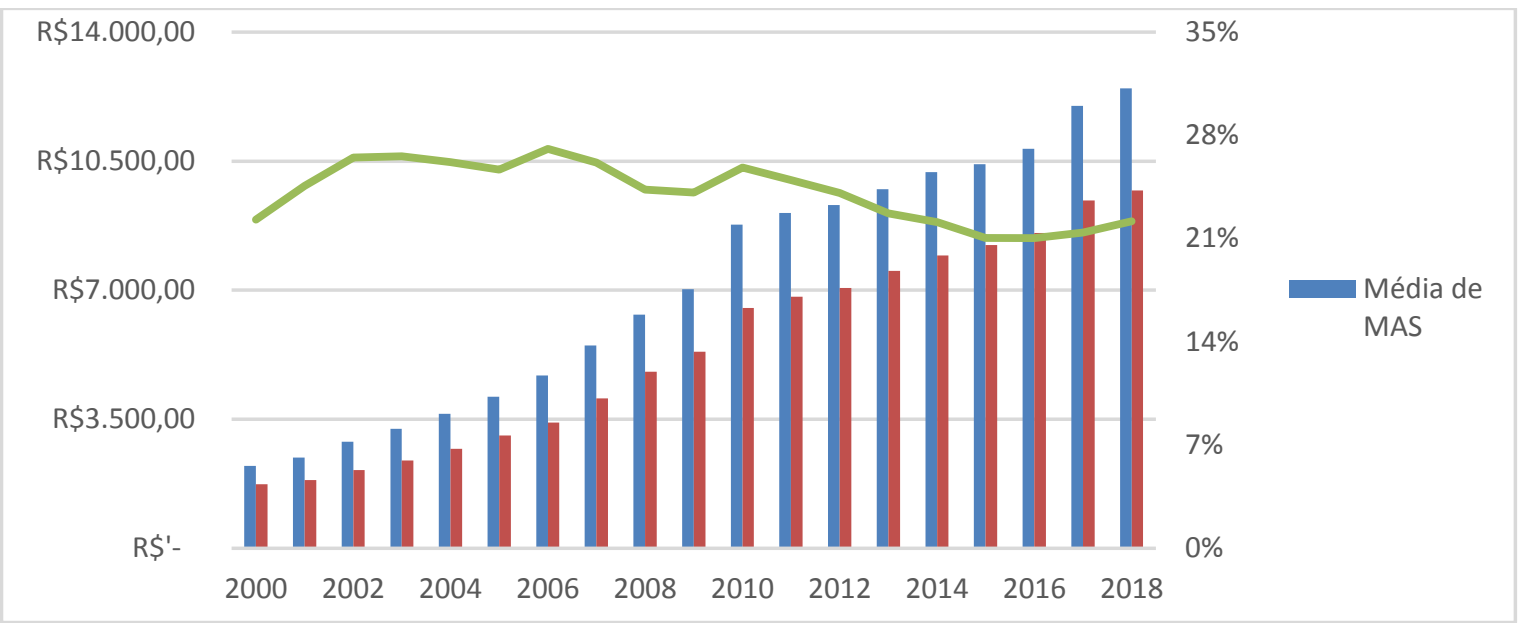

Fonte: elaboração dos autores, a partir dos dados do SIAPE referente a março de 2018.

Ao voltarmos para os dados fornecidos pelo SIAPE de março de 2017, na categoria de todos os servidores e servidoras ativos, tem-se que $74,82 \%$ dos servidores possuem grau de escolaridade igual ou maior do que ensino superior. No entanto, ao analisarmos a escolaridade por sexo, observamos que dentre as mulheres, $80,24 \%$ possuem grau de escolaridade superior ou acima, perfazendo o total de $35,94 \%$ de todos os servidores públicos federais dentro desta faixa de formação acadêmica. Já entre os homens, $70,42 \%$ possuem ensino superior ou pós-graduação Stricto ou lato sensu, perfazendo $38,88 \%$ do montante total.

Tabela 3: Grau de Escolaridade por gênero

\begin{tabular}{|c|c|c|c|c|c|c|}
\hline \multirow{2}{*}{$\begin{array}{l}\text { Grau } \\
\text { Escolarida } \\
\text { de }\end{array}$} & \multicolumn{2}{|l|}{ Mulher } & \multicolumn{2}{|l|}{ Homem } & \multicolumn{2}{|c|}{ Total Geral } \\
\hline & $\mathbf{N}$ & $\%$ & $\mathbf{N}$ & $\%$ & $\mathbf{N}$ & $\%$ \\
\hline $\begin{array}{l}\text { Ate } \\
\text { Fundament } \\
\text { al }\end{array}$ & 7.596 & $1,17 \%$ & 27.905 & $4,30 \%$ & 35.501 & $5,47 \%$ \\
\hline $\begin{array}{l}\text { Ensino } \\
\text { Médio }\end{array}$ & 49.791 & $7,67 \%$ & 78.082 & $12,03 \%$ & 127.873 & $19,71 \%$ \\
\hline Superior & 123.043 & $18,96 \%$ & 140.452 & $21,65 \%$ & 263.495 & $40,61 \%$ \\
\hline Mestrado & 26.242 & $4,04 \%$ & 23.175 & $3,57 \%$ & 49.417 & $7,62 \%$ \\
\hline Doutorado & 48.278 & $7,44 \%$ & 60.768 & $9,37 \%$ & 109.046 & $16,81 \%$ \\
\hline $\begin{array}{l}\text { Pós } \\
\text { Graduacao }\end{array}$ & 35.707 & $5,50 \%$ & 27.810 & $4,29 \%$ & 63.517 & $9,79 \%$ \\
\hline
\end{tabular}




\begin{tabular}{|l|l|l|l|l|l|l|}
\hline $\begin{array}{l}\text { Sem_infor } \\
\text { mação }\end{array}$ & 3 & $0,00 \%$ & 28 & $0,00 \%$ & 31 & $0,00 \%$ \\
\hline $\begin{array}{l}\text { Total Geral } \\
\text { Col. }\end{array}$ & 290.660 & $\mathbf{4 4 , 7 9 \%}$ & $\mathbf{3 5 8 . 2 2 0}$ & $\mathbf{5 5 , 2 1 \%}$ & $\mathbf{6 4 8 . 8 8 0}$ & $\mathbf{1 0 0 , 0 0 \%}$ \\
\hline
\end{tabular}

Fonte: elaboração dos autores, a partir dos dados do SIAPE referente a março de 2018.

Os dados abaixo retratam o serviço civil da administração pública federal em 2018, segundo os mesmos, a categoria de maior remuneração, acima de $R \$ 12.000,00$, é recebida percentualmente por mais homens do que mulheres, em todos os níveis de escolaridade.

Gráfico 5: Remuneração média por sexo e escolaridade do serviço civil da administração pública federal

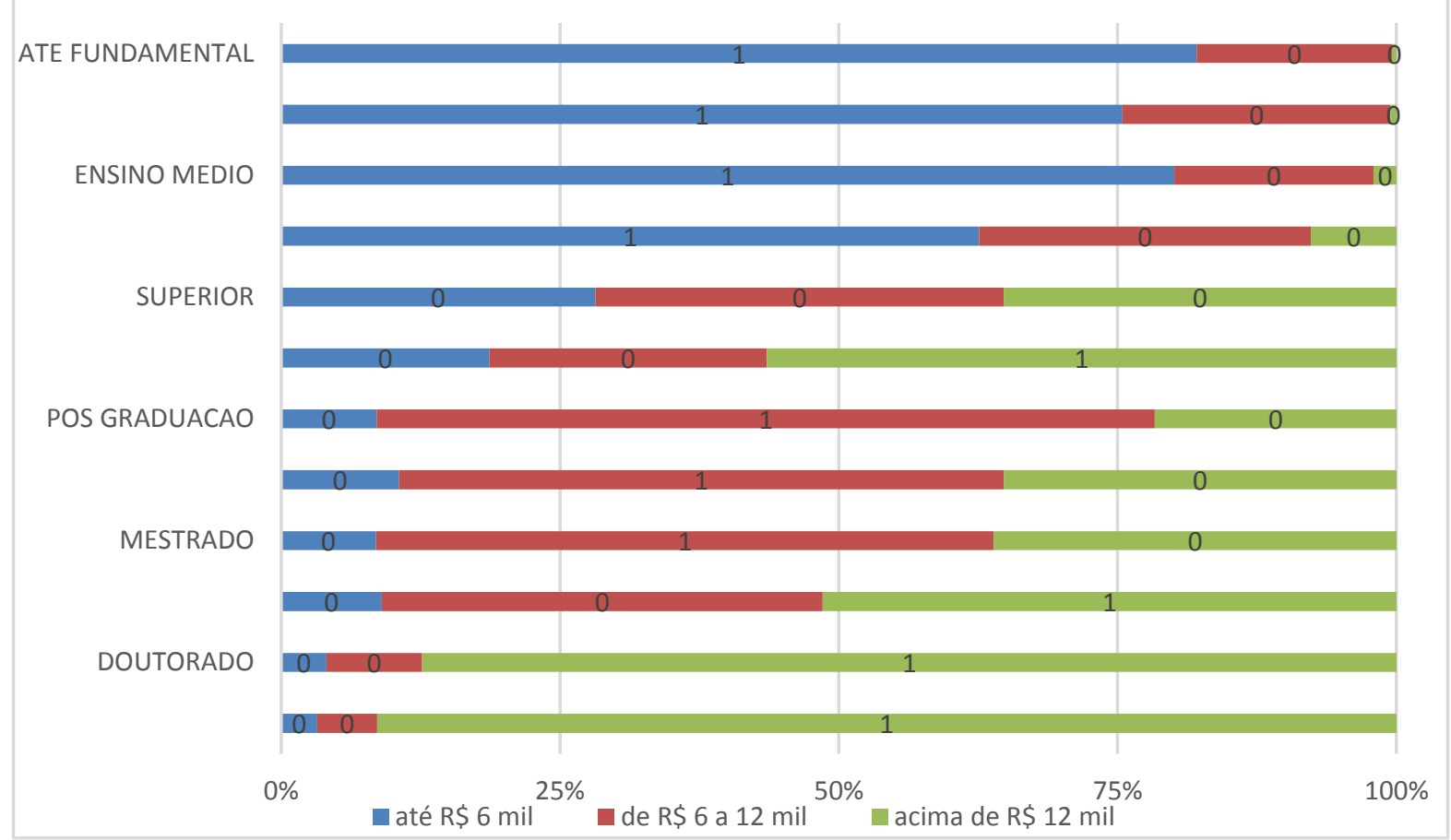

Fonte: elaboração dos autores, a partir dos dados do SIAPE referente a março de 2018.

Desta forma, a escolaridade não pode ser atribuída como determinante para a diferença na remuneração entre mulheres e homens na administração pública federal, uma vez que em todos os níveis de escolaridade recebem salários menores do que os homens.

Ao analisarmos a distribuição dos cargos em comissão (DAS/FCPE) por sexo no serviço civil da administração pública federal, tem-se que $57,8 \%$ dos cargos são ocupados por homens e $42,19 \%$ por mulheres. 
Gráfico 6: Ocupação de cargo em comissão (DAS/FCPE) por sexo no serviço civil da administração pública federal

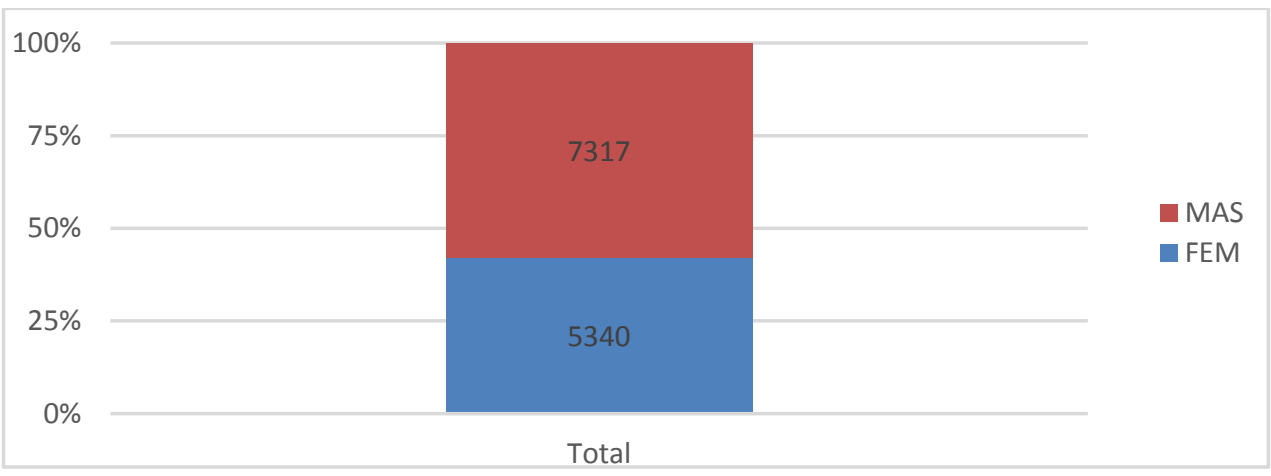

Fonte: elaboração dos autores, a partir dos dados do SIAPE referente a março de 2018.

Dentre os homens, $14,06 \%$ ocupam cargos em comissão, já entre o total de mulheres, esse percentual cai para $12,07 \%$.

Gráfico 7: Ocupação de cargo em comissão (DAS/FCPE) para mulheres e homens no serviço civil da administração pública federal

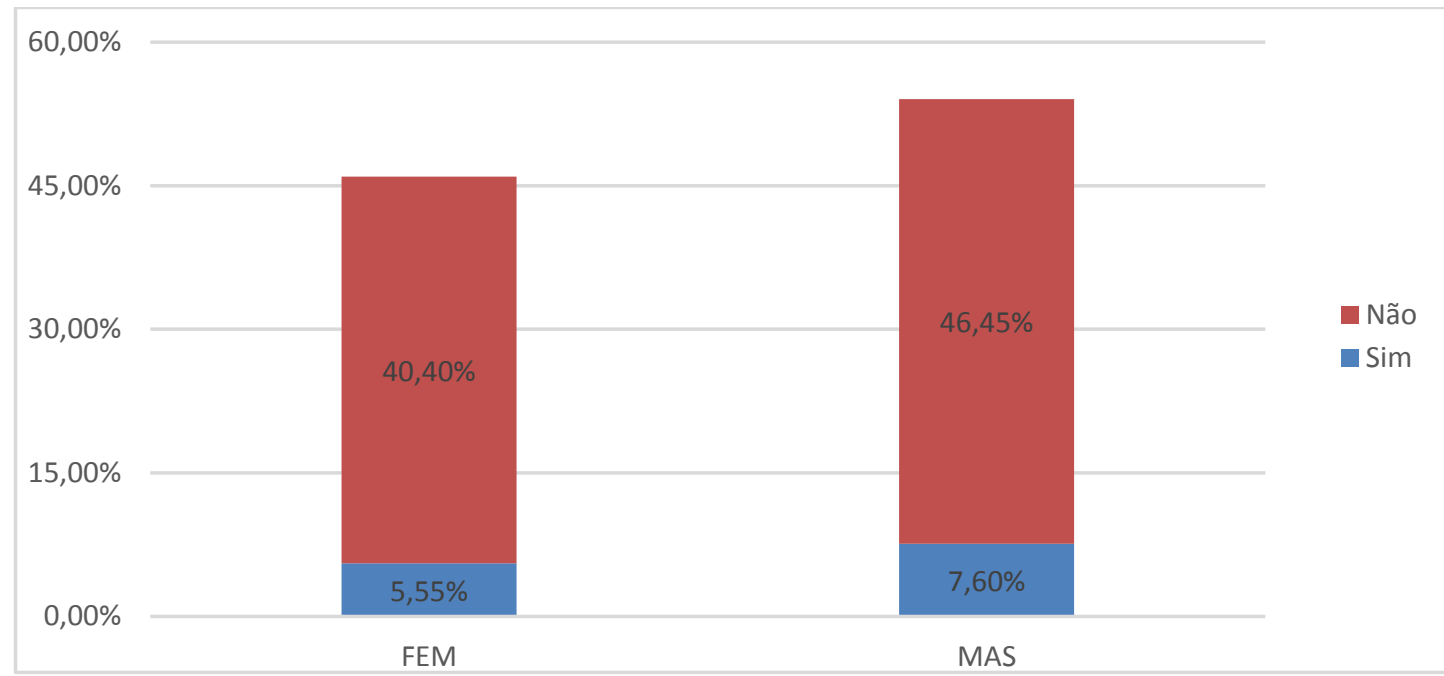

Fonte: elaboração dos autores, a partir dos dados do SIAPE referente a março de 2018.

Ao analisarmos a série temporal, observamos que, durante todo o período analisado, os maiores percentuais alcançados pelas mulheres na ocupação de cargos estiveram entre os DAS/FCPE 1 a 3, ou seja aqueles com menor responsabilidade na tomada de decisão, gerenciamento de equipes, e também com menores valores remuneratórios. As mulheres atingiram o maior patamar de ocupação do DAS/FCPE 6 , correspondente ao de Secretários de Estado, com grande poder de tomadas de decisão e gerenciamento de recursos e equipes, na medição de setembro de 2010, quando ocuparam 26\% dos DAS/FCPE 6 do serviço civil. O menor patamar de ocupação das mulheres do DAS/FCPE 6 foi alcançado em setembro de 2016, quando alcançaram o patamar de 10\%, sendo que em março de 2018 o índice alcançou 14\%.

A constante baixa taxa de ocupação de cargos de tomada de decisão da burocracia brasileira parece 
acompanhar a também baixa ocupação da representação política das mulheres no Brasil. Segundo ranking elaborado pela ONU Mulheres em parceria com a Inter-Parliamentary Union (IPU) intitulado "Women in Politics" ${ }^{\prime}$, em janeiro de 2019 de um ranking de 192 países o Brasil ocupava a 134a posição na paridade de gênero na ocupação dos parlamentos, e o $149^{a}$ posição na paridade de gênero na ocupação de cargos ministeriais.

Dessa forma, a desigual representação burocrática das mulheres nos altos cargos de confiança, no Brasil, é acompanhada por uma também desigual representação das mulheres nos cargos políticos de tomada de decisão, haja vista que a baixa representação política de mulheres também se repete na ocupação de cargos nos executivos e legislativos estaduais e municipais brasileiros.

Gráfico 7: Percentual de mulheres em cargos em comissão

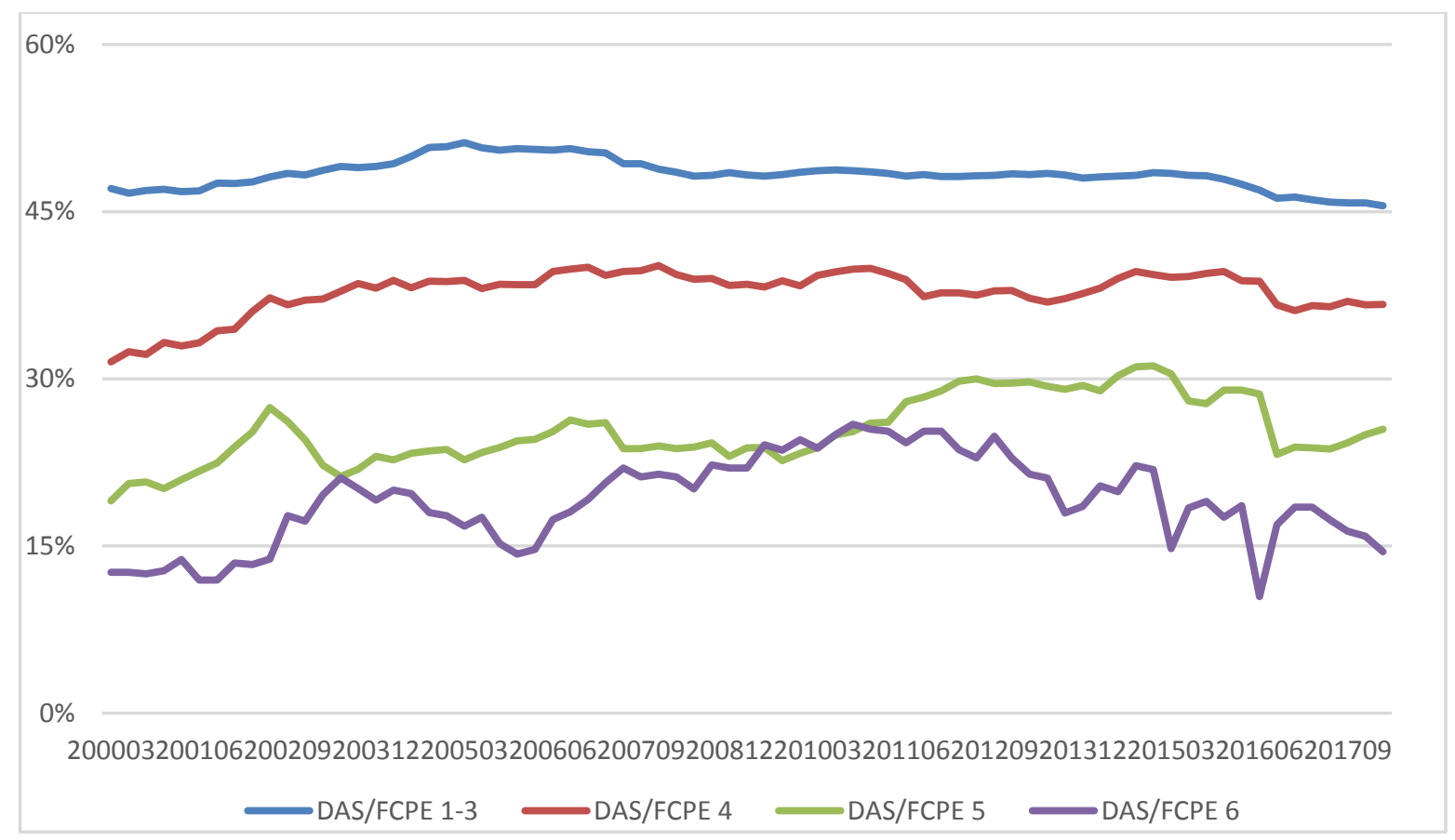

Fonte: elaboração dos autores, a partir dos dados do SIAPE referente a março de 2018.

O debate sobre a ocupação de cargos de liderança por mulheres é uma das discussões cada vez mais recorrente na literatura internacional e nacional. Nesse sentido, um dos achados é a constatação de que as mulheres têm ascendido até os primeiros patamares de liderança, mas os patamares mais elevados de liderança são barrados a elas, por meio de diversas formas, como se houvesse um "teto de vidro" que as impedisse de continuar galgando os espaços mais influentes na tomada de decisão (Fontenele-Mourão, 2006; Isaac et. al., 2012; Vaz, 2015).

A partir dos dados da ocupação de cargos em comissão por sexo no serviço civil da administração pública federal, percebemos a existência do teto de vidro exatamente na passagem dos cargos DAS/FCPE 3 para os de DAS/FCPE 4. Os cargos DAS/FCPE de 1 a 3 correspondem a cargos de baixo escalão, os DAS/FCPE 4 e 5, de médio escalão, e o DAS/FCPE 6 assim como os cargos de natureza especial, são considerados cargos de alto escalão (Lotta et. al.,2015). Dessa forma, na ocupação dos cargos em confiança de maior

\footnotetext{
${ }^{7}$ http://www.unwomen.org/en/digital-library/publications/2019/03/women-in-politics-2019-map
} 
responsabilidade há uma inversão no percentual de cargos ocupados por homens e mulheres, esse teto de vidro é uma barreira que se reproduz ao longo dos anos.

Gráfico 8 : Ocupação de cargo em comissão (DAS/FCPE), por cargo, por sexo no serviço civil da administração pública federal

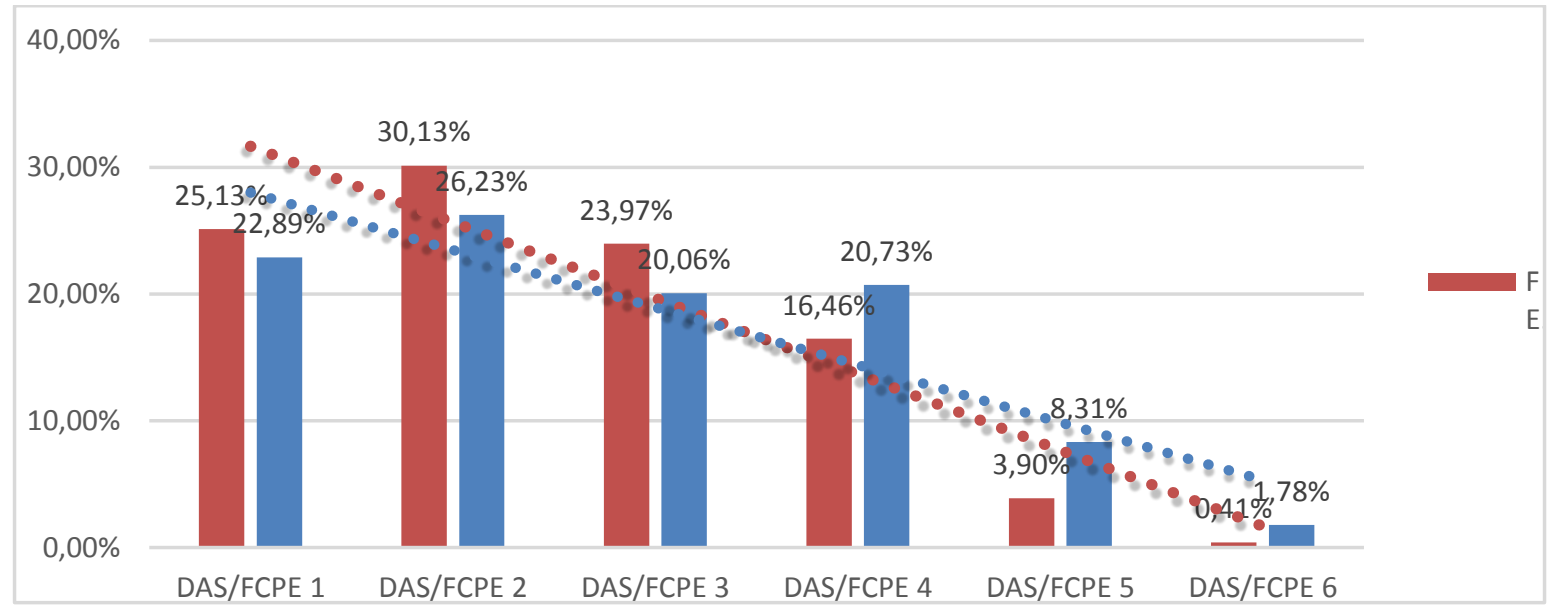

Fonte: elaboração dos autores, a partir dos dados do SIAPE referente a março de 2018.

A desigualdade de gênero na representação passiva resta evidenciada a partir dos dados acima expostos, no entanto, poucos estudos nacionais avançaram até agora sobre os impactos da representação passiva na representação ativa da burocracia. $O$ ingresso em um ambiente organizacional específico exige do burocrata a convivência com valores, cultura organizacional, e um ambiente hierárquico consolidado no qual o novo ingressante terá que adaptar-se. Desta forma, a promoção da mudança institucional não é simples, envolvendo uma série de dinâmicas sedimentadas ao longo da trajetória das instituições.

A tabela abaixo nos dá algumas pistas sobre a especialização de funções em razão de sexo no serviço civil da administração pública federal. As atividades foram agrupadas em quatro grandes grupos a partir dos tipos de atividades: "articulação e representação", "atividades analíticas", "gestão de parcerias" e finalmente "atividades administrativas". Foi perguntado no survey encaminhado a pessoas que integram o serviço civil da administração pública federal a frequência com que desempenham cada uma das atividades abaixo, em um índice que variou de " 1 . Nunca" até " 5 . Todos" os dias. Os resultados abaixo apresentados mais próximos ao número 1 representam uma frequência maior de desempenho de determinada atividade pelos respondentes, bem como os resultados mais distantes no número 1, uma menor frequência no desempenho das atividades.

Ao observar a tabela verificamos que, nos três primeiros grupos de atividades - "articulação e representação", "atividades analíticas", "gestão de parcerias" - há variações na frequência por tipos de atividade por sexo, mas em nenhum caso estas variações extrapolam uma unidade da primeira casa decimal, indicando frequências muito próximas entre servidoras e servidores civis no desempenho das atividades destas categorias. Quando observamos o quarto grupo, "atividades administrativas", o qual contém apenas um tipo de atividade, expresso por meio do descritor: "Realizar atividades administrativas, tais como agendamento de reuniões, tramitação de processos, compra de passagens, elaboração de ofícios e memorandos" verificamos que é a atividade com maior frequência realizada pelas mulheres que integram o serviço civil da administração pública federal e, por outro lado, a atividade com menor peso desempenhada entre os homens que integram as mesma categoria. 
Não são poucos os relatos no serviço público de servidoras que, em situações nas quais possuíam a mesma carreira e/ou cargos de colegas do sexo masculino, são elas as responsabilizadas e primeiramente lembradas para elaborar atas de reuniões, pedir água e café, e realizar as demais atividades administrativas.

Tabela 4: Análise Fatorial das Atividades por gênero (Questão 11 - Com que frequência você executa as atividades abaixo relacionadas à política pública na qual desempenha suas funções?)

\begin{tabular}{|c|c|c|c|c|c|c|c|}
\hline \multirow{2}{*}{ Atividades } & \multicolumn{4}{|c|}{ Mulher } & \multicolumn{3}{|c|}{ Homem } \\
\hline & 1 & 2 & 3 & 4 & 1 & 2 & \\
\hline $\begin{array}{l}\text { Representar o órgão em eventos, reuniões e } \\
\text { atividades externas }\end{array}$ &, 825 & & & &, 764 & & \\
\hline $\begin{array}{l}\text { Negociar e coordenar ações com outros órgãos } \\
\text { da administração federal que participem da } \\
\text { implementação da política pública }\end{array}$ &, 809 & & & &, 772 & & \\
\hline $\begin{array}{l}\text { Participar de grupos de trabalho ou projetos } \\
\text { comuns com outras áreas do seu órgão }\end{array}$ &, 735 & & & & ,697 & & \\
\hline $\begin{array}{l}\text { Consultar e atender grupos interessados da } \\
\text { sociedade sobre questões que envolvam a } \\
\text { política pública }\end{array}$ &, 697 & & & & ,687 & & \\
\hline $\begin{array}{l}\text { Pactuar e gerir ações com entes governamentais } \\
\text { estaduais ou municipais }\end{array}$ &, 630 & & & &, 518 & & \\
\hline Organizar eventos &, 621 & & & & ,686 & & \\
\hline Coordenar equipe &, 520 & & & & ,456 & & \\
\hline $\begin{array}{l}\text { Elaborar textos normativos (ex. projetos de lei, } \\
\text { decretos, portarias, etc.) }\end{array}$ & 478 & & & &, 543 & & \\
\hline $\begin{array}{l}\text { Fiscalizar o cumprimento das normas e } \\
\text { regulamentos da política pública }\end{array}$ & & $\begin{array}{l}, 65 \\
0\end{array}$ & & & & ,656 & \\
\hline $\begin{array}{l}\text { Operacionalizar bases de dados e sistemas de } \\
\text { informação que apoiam a implementação da } \\
\text { política pública }\end{array}$ & & $\begin{array}{l}, 62 \\
7\end{array}$ & & & & ,642 & \\
\hline
\end{tabular}




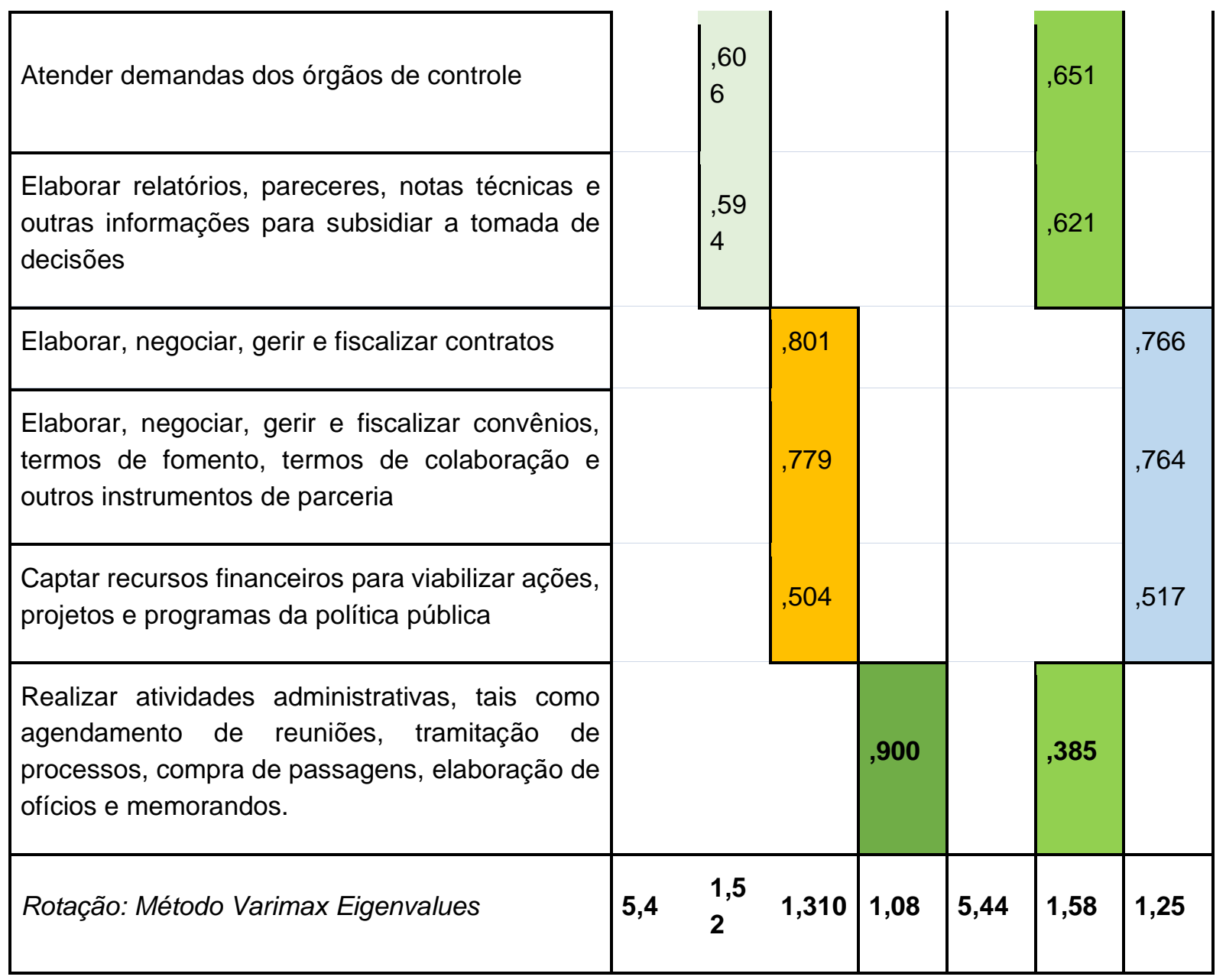

Fonte: Fonte: Elaboração dos autores a partir dos dados da pesquisa Capacidades Estatais Enap/2018

O sistema de gênero construído a partir da divisão sexual do trabalho expande seus tentáculos para os mais tênues processos e procedimentos de organização do trabalho no serviço civil da administração pública federal. Quais serão as implicações desta desigualdade na elaboração e implementação de políticas públicas?

No que diz respeito ao recorte de raça, a tabela 4 apresenta as estimativas para o ajuste do modelo de regressão como modelo 'mulher', com as variáveis significativas ao nível de significância de $99 \%$ de confiança. Pode-se verificar que a estimativa da média global de remuneração das mulheres é de $\mathrm{R} \$ 5.935,88$. Observa-se, também, que as variáveis "se o servidor possui grau de escolaridade superior (Se_GRAU_ESCOLSUP)" e "Se possui vínculo de DAS (Se_Possui_VINCDAS)" impactam positivamente na remuneração. Por outro lado, como contribuição negativa sobre a remuneração, estão o gênero é mulher (Se_Gênero_F) e a raça (não branco), demonstrando padrões de desigualdades sobre a renda em razão do gênero e da raça dentro do setor público federal. 
Tabela 5: Modelo de Regressão como 'mulher'

\begin{tabular}{|c|c|c|c|c|c|}
\hline \multirow{2}{*}{$\begin{array}{l}\text { Modelo } \\
\text { Mulher } \\
\text { Variável }\end{array}$} & \multicolumn{2}{|c|}{$\begin{array}{l}\text { Coeficientes } \\
\text { padronizados }\end{array}$} & \multirow{2}{*}{$\begin{array}{l}\text { Coeficiente } \\
\text { padronizados } \\
\text { E.P. Beta }\end{array}$} & \multirow{2}{*}{ t-value } & \multirow{2}{*}{$p$-valor } \\
\hline & $\begin{array}{l}\text { Estimativa } \\
\text { Beta }\end{array}$ & Erro Padrão & & & \\
\hline (Constant) & $5.935,88$ & 19,82 & & 299,46 & $<0,000$ \\
\hline Se_Gênero_F & $-1.538,27$ & 13,81 & $-0,13$ & $-111,37$ & $<0,000$ \\
\hline Raça & $-67,63$ & 4,36 & $-0,02$ & $-15,50$ & $<0,000$ \\
\hline $\begin{array}{l}\text { Se_GRAU_E } \\
\text { SCOLSUP }\end{array}$ & $4.514,34$ & 15,60 & 0,34 & 289,33 & $<0,000$ \\
\hline $\begin{array}{l}\text { Se_Possui_VI } \\
\text { NCDAS }\end{array}$ & $1.541,24$ & 16,67 & 0,11 & 92,45 & $<0,000$ \\
\hline
\end{tabular}

Fonte: elaboração dos autores, a partir dos dados do SIAPE referente a março de 2018.

A Tabela 5 apresenta as estimativas para o ajuste do modelo de regressão como modelo masculino, com as variáveis ao nível de significância de $99 \%$ de confiança. Pode-se verificar que estimativa da média global de remuneração dos homens é de $\mathrm{R} \$ 4.397,60$. Como variáveis que possuem impacto positivo sobre a remuneração estão "Se o servidor possui grau de escolaridade superior (Se_GRAU_ESCOLSUP)", "Se possui vínculo de DAS (Se_Possui_VINCDAS)" e "Se o indivíduo é do gênero masculino (Se_Gênero_M)". Por outro lado, observa-se que a única variável com peso negativo sobre a renda é a de raça, demonstrando que a desigualdade remuneratória no grupo 'masculino' dar-se o indivíduo na comparação entre os subgrupos 'brancos' e 'não-brancos'.

Tabela 6: Modelo de Regressão como 'masculino'

\begin{tabular}{|c|c|c|c|c|c|}
\hline \multirow{2}{*}{$\begin{array}{l}\text { Modelo } \\
\text { Masculino } \\
\text { Variável }\end{array}$} & \multicolumn{2}{|c|}{ Unstandardized Coefficients } & \multirow{2}{*}{$\begin{array}{l}\text { Standardized } \\
\text { Coefficients } \\
\text { E.P. Beta }\end{array}$} & \multirow{2}{*}{ t-value } & \multirow{2}{*}{$p$-Valo } \\
\hline & $\begin{array}{l}\text { Estimativa } \\
\text { Beta }\end{array}$ & Erro Padrão & & & \\
\hline (Constant) & $4.397,60$ & 20,88 & & 210,58 & $<0,000$ \\
\hline $\begin{array}{l}\text { Se_Genero_ } \\
\text { M }\end{array}$ & $1.538,27$ & 13,81 & 0,13 & 111,37 & $<0,000$ \\
\hline
\end{tabular}




\begin{tabular}{|l|l|l|l|l|l|}
\hline Raça & $-\mathbf{6 7 , 6 3}$ & 4,36 & $-0,02$ & $-15,50$ & $<0,000$ \\
\hline $\begin{array}{l}\text { Se_GRAU_E } \\
\text { SCOLSUP }\end{array}$ & $\mathbf{4 . 5 1 4 , 3 4}$ & 15,60 & 0,34 & 289,33 & $<\mathbf{0 , 0 0 0}$ \\
\hline $\begin{array}{l}\text { Se_Possui_VI } \\
\text { NCDAS }\end{array}$ & $\mathbf{1 . 5 4 1 , 2 4}$ & 16,67 & 0,11 & 92,45 & $<\mathbf{0 , 0 0 0}$ \\
\hline
\end{tabular}

Fonte: elaboração dos autores, a partir dos dados do SIAPE referente a março de 2018.

Comparando os dois modelos propostos Mulher e Homem na Eq. (1) e (2), verifica-se que, mesmo sob as mesmas condições (atribuindo 1 para Grau de Escolaridade Superior, atribuíndo-se 1 para se Possui DAS, e se é do gênero correspondente), obtêm-se as seguintes remunerações apresentadas na tabela 6, abaixo, nota-se que as variáveis gênero e raça possuem efeitos negativos sobre a remuneração:

Tabela 7: Estimativas obtidas dos modelos propostos Mulher (1) e Homem (2) por Raça.

\begin{tabular}{|c|c|c|c|}
\hline Indicador & Raça & Mulher & Homem \\
\hline 1 & Branca & $10.385,55$ & $11.923,82$ \\
\hline 2 & Parda & $10.317,92$ & $11.856,19$ \\
\hline 3 & Preta & $10.250,28$ & $11.788,56$ \\
\hline 4 & Amarela & $10.182,65$ & $11.720,92$ \\
\hline 5 & Indígena & $10.115,01$ & $11.653,29$ \\
\hline 6 & Outros & $10.047,38$ & $11.585,65$ \\
\hline
\end{tabular}

Fonte: elaboração dos autores, a partir dos dados do SIAPE referente a março de 2018.

Em síntese, os dados acima mostram que os subgrupos 'mulheres' e 'não-brancos' recebem uma remuneração menor, comparando-se com os subgrupos 'homens' e 'brancos'. Portanto, os resultados sugerem que o setor público federal também reproduz desigualdades no que diz respeito ao padrão de remuneração, acompanhando as desigualdades presentes não só no mercado de trabalho brasileiro, mas, também, na América Latina (Cepal, 2018).

\section{Considerações Finais}

Este trabalho insere-se na trajetória das pesquisas que têm procurado entender o perfil de gênero e raça da burocracia federal. Portanto, procurou compreender a atuação da administração pública federal enquanto empregadora na reprodução das desigualdades de gênero e raça presentes no mercado de trabalho.

A sociedade brasileira caracteriza-se por ser uma das mais desiguais do planeta. A dinâmica da extremada 
disparidade de renda acontece acoplada ao processo de hierarquização das diferenças. Desta forma, a imensa diversidade étnica, territorial, de gênero, racial constituinte da sociedade brasileira é traduzida em processos de hierarquização e exclusão social. Por sua vez, a literatura vem mostrando como a atuação dos burocratas, sejam eles de nível de rua, médio ou alto escalão, influencia a produção e a implementação das políticas públicas. Esses burocratas agem a partir de seus interesses, manifestam preferências, e gerem poder, conhecimento, oportunidades no complexo processo de gestão e produção de políticas públicas. $\mathrm{Na}$ sociedade em geral o processo de hierarquização das diferenças materializa-se em discriminação, preconceito, violência de gênero e opressões de diferentes ordens. O trabalho procurou refletir sobre como se materializam os processos de hierarquização de gênero e raça no serviço civil brasileiro.

Os principais resultados da pesquisa mostram a variável gênero tem impacto negativo em diversas formas, quais sejam: ocupação de cargos com maior valor social, papel social de gênero em termos de atividades desempenhadas e, por conseguinte, na menor remuneração, comparando-se com o subgrupo 'homens'. No que diz respeito à variável raça, a partir de uma regressão, percebe-se que o fato de ser do sub-grupo 'nãobranco' tem impacto negativo direto na remuneração, seja mulher, seja homem. Nesse sentido, os dados sugerem que o setor público federal também reproduz desigualdades, à luz de um recorte de gênero e raça.

Portanto, entendemos que os dados aqui apresentados contribuem para reflexão acerca dos padrões de desigualdade do setor público federal. Se, de fato, desejamos ter um Estado que possa ter o importante papel na redução das imensas - e históricas - desigualdades sociais brasileiras, parece-nos que, de partida, devemos questionar se esse Estado também não tem colaborado para (re)produção dessa desigualdade.

Os dados deste artigo possibilitam o diálogo com a dimensão 'passiva' da teoria de Burocracia Representativa. Podemos afirmar, à luz dos dados e desta abordagem, que a burocracia do Setor Público Federal não possui uma representação passiva, especialmente na sua dimensão racial, uma vez que a porcentagem de servidores 'não-brancos' é muito inferior, comparando-se a proporção deste grupo no total da população brasileira. Só esse dado já nos permite afirmar que políticas afirmativas para concursos públicos e preenchimento de cargos comissionados são fundamentais para a redução de desigualdades.

Como limites do artigo, os quais também podem ser pensados como agenda de pesquisa futura, refletimos se o fato da burocracia brasileira afastar do conceito de representação passiva nas dimensões de classe, mas também nas de gênero e raça, contribuem para que os processos de aprofundamento da desigualdade sejam perpetuados por esta burocracia. Além disso, ressaltamos que pesquisas que abordem a dimensão 'ativa' desta representação burocrática são importantes a fim de que possamos efetivamente compreender o comportamento desses burocratas, os quais, no limite, materializam o poder estatal no cotidiano, produzindo efeitos distributivos, os quais, no limite, impactam a vida de pessoas, especialmente as que estão em condições de vulnerabilidade.

\section{Referências}

Andrews, R., Boyne, G. A., Meier, K. J., O'Toole, J. and Walker, R. M. (2005). Representative

Bureaucracy, Organizational Strategy, and Public Service Performance: An Empirical Analysis of English Local Government. Journal of Public Administration Research and Theory 15(4): 489-504.

Cepal. 2019. Panorama Social da América Latina. 31.p.

Enap. (2018). Capacidades estatais para produção de políticas públicas: resultados do survey sobre serviço civil no Brasil. Cadernos Enap, 56, 74.

Fontenele - Mourão. Mulheres no topo de carreira - flexibilidade e persistência. Secretaria Especial de Políticas para Mulheres, Brasília: 2006.

Groeneveld, S. (2015). Explaining diversity management outcomes. What can be learned from quantitative 
survey research? in: Bendl, R., Bleijenbergh, I., Henttonen, E. and Mills, A. (eds.). Oxford Handbook of Diversity in Organisations. Oxford: Oxford University Press.

Hirata, Helena; Kergoat, Danièle. 2008. Divisão sexual do trabalho profissional e doméstico: Brasil, França, Japão.

Ipea, 2014. Boletim de política social. Antonio Teixeira Lima Junior, Elizabeth Marins, Luana Simões Pinheiro, Luciana da Luz Silva e Natália de Oliveira Fontoura.

Ipea, 2019. Os desafios do passado no trabalho doméstico do século XXI: reflexões para o caso brasileiro a partir dos dados da Pnad Contínua.

ISAAC, Carol A. KATZ, Anna. CARNES, Molly. Deconstructing the Glass Ceiling. Sociology Mind, Vol. 2, No. 1, 80-86. January 2012. (http://www.SciRP.org/journal/sm)

Kingsley, J.D. (1944). Representative Bureaucracy. Yellow Springs: Antioch Press.

Keiser, L.R., Wilkins, V.M., Meier, K.J., and Holland, C.A. (2002). Lipstick and Logarithms: Gender, Institutional Context, and Representative Bureaucracy. American Political Science Review 96(3): 553-564.

LIPSKY, Michael. (1980) Street-level bureaucracy: dilemmas of the individual in public services. Nova York: Russel Sage Foundation.

LOTTA, Gabriela. O papel das burocracias do nível da rua na implementação de políticas públicas: entre o controle e a discricionariedade. In: FARIA, C. A (org). Implementação de Políticas Públicas. Teoria e Prática. Editora PUCMINAS, Belo Horizonte, 2012.

Lotta, Gabriela Spanghero. Pires, Roberto Rocha Coelho. Oliveira, Vanessa Elias de. Burocratas de médio escalão: novos olhares sobre velhos atores da produção de políticas públicas. In: Burocracia de médio escalão: perfil, trajetória e atuação / organizadores Pedro Luiz Costa Cavalcante e Gabriela Spanguero Lotta. - Brasília: ENAP, 2015.

Meier, K. J. (1975). Representative Bureaucracy: An Empirical Analysis. The American Political Science Review 69(2): 526-542.

Meier, Kenneth J., Robert D. Wrinkle, and J. L. Polinard. 1999. Representative Bureaucracy andDistributional Equity: Addressing the Hard Question, Journal of Politics61(4): 1025-39.

Meier, K. J. and Nicholson-Crotty, J. (2006). Gender, representative bureaucracy, and law enforcement: The case of sexual assault. Public Administration Review 66(6): 850-860.

Mosher, F. C. (1968). Democracy and the Public Service. New York: Oxford University Press.

Pestana, m. H. \& gageiro, j. N. 2005. Análise de Dados para Ciências Sociais: A Complementaridade do SPSS. Lisboa, Edições Sílabo.

Pires, Roberto and Lotta, Gabriela. 2019. Burocracia de nível de rua e (re)produção de desigualdades sociais: comparando perspectivas de análise. In: Implementando desigualdades: reprodução de desigualdades na implementação de políticas públicas. Roberto Rocha C. Pires Organizador. Rio de Janeiro : Ipea.

Selden, S. C. (1997). Representative Bureaucracy: Examining the Linkage between Passive and Active Representation in the Farmers Home Administration. The American Review of Public Administration, 27(1), $22-42$.

VAZ, D. V. (2015). O teto de vidro nas organizações públicas: evidências para o Brasil. Economia e Sociedade, 22(3), 765-790. Recuperado de https://www.periodicos.sbu.unicamp.br/ojs/index.php/ecos/article/view/8642183 